\title{
A Review on Interaction of Nanoplastics with Aquatic Environment and Organisms
}

\author{
Prerna Rathor*, Alfred Mech, Naveed Anayat, Tushar Subhra Khanra, \\ Zhovi Ringa and Saikat Maity
}

Department of Fisheries, Doon PG College-Uttarakhand, India

*Corresponding author

\section{A B S T R A C T}

\section{Ke y w o r d s \\ Nanoplastics, Toxic effects, Aquatic environment, Environmental impact}

\section{Article Info}

\section{Accepted:}

22 January 2021

Available Online:

10 February 2021
Since the refinements in progression of new age plastics, nanoplastics have gained the research and public attention because of its repercussions on the aquatic environment as well as aquatic biota. The term 'nanoplastics' is perpetually referred to plastic particles having a particle size $<100 \mathrm{~nm}$. Because of their diminutive size and high surface area, these nanoplastics are more susceptible to assimilate fatal chemicals from their adjoining environment. Smaller size of nanoplastics facilitates their accumulation in organism's body and even their transfer among food chains. Several studies show that nanoplastics have detrimental effects on the growth and spawning of organisms along with interference in the metabolic proficiency. Even though nanoplastics have hazardous impact on both marine as well as freshwater systems, astoundingly only few studies have been there comprehending nanoplastics. This review focuses on bringing comprehensive overview of the literature of the interaction of nanoplastics with aquatic environment and organisms.

\section{Introduction}

Lately, aquatic pollution of marine and freshwater environments due to various anthropogenic activities has been a topic of concern for scientists as well as public (Forouhar et al., 2018). Bakelite (a phenolformaldehyde resin) was the first synthetic polymer which was mass produced in 1909 (Vlachopoulos and Strutt, 2003). Thereafter, the contemporary forms of PVC, more processable polystyrene (PS), polyethylene terephthalate (PET) and polyurethane (PUR) were developed during 1930s (Brandsch and Piringer, 2008). After the mass production of plastic in early 1940s, millions of tonnes of plastics have been manufactured worldwide. In 2015, amount of plastic produced reached 322 milliontonnes (Plastics Europe, 2016) which was earlier 280 million tonnes in 2012 (Rochman and Browne, 2013). Plastics production has widely increased due to their use in commercial and strategic sectors such as in packaging (39.9\%), agriculture(3.3\%), the automotive industry (10\%), construction $(19.7 \%)$, electronics $(6.2 \%)$, households and sports $(4.2 \%)$ and rest in medical fields and furniture industry (Horton et al., 2017).Till now, plastics wastes have been detected in lakes (Xiong et al., 2018b), oceans (Mendoza 
et al., 2018), soils (Zhang and Liu, 2018), sediments (Abidliet al., 2018), and even in extreme regions like Arctic (Cozar et al., 2017) and Antarctic (Munari et al., 2017). Various recent reviews address the sources and harmful effects of plastic scraps on environment. Due to the chemical stability, bioaccumulation and persistence of plastics, the problem of plastic pollution in the environment is becoming increasingly eminent (Shen et al., 2019). Plastic wastes can be degenerated into tiny shards or fragments due to erosion, Ultraviolet illumination and decomposition by biological activities. The plastic species having particle sizes $<5 \mathrm{~mm}$ are defined as microplastics (Thompson et al., 2018). The utmost sources of these microplastics are mainly cosmetic products and detergents that contain small plastic particles (Lei et al., 2017). Further, these microplastics could be divided into primary and secondary microplastics. Primary microplastics comprises of manufactured plastics having microscopic size, for example those used in cosmetics or industrial pellets that serves as precursor for produced plastic products. Secondary microplastics are acquired from macroscopic detritus due to the influence of oxidation, mechanical forces and photochemical processes (Hidalgo-Ruzet al., 2012). A top-down approach for the synthesis of polyethylene nanoparticles was investigated and it was found that nanoparticles were result of mechanical degradation of primary and secondary microplastics, and these particles showed heterogenous shapes and sizes, mimicking particles from the marine environment (El Hadri et al., 2020). Microplastics can be further degraded to nanoplastics, having size $<100 \mathrm{~nm}$ (Jambeck et al., 2015). Nanoparticles are defined as materials with dimensions between 1 and $100 \mathrm{~nm}$ (Klaine et al., 2008). Among plastic particles, nanoplastics are of certain interest because of their nano-specific characteristics, which profoundly vary from those of the same polymer type in bulk form (Klaine et al., 2012). Due to the considerably small particle size, nanoplastics are widely distributed in the aquatic environment and can be easily ingested by organisms. The larger surface area of nanoplastics may cause atypically strong adsorption affinities for toxic aggravates (Velzeboer et al., 2014a) possibly leading to cumulative particle and chemical lethal effects once nanoparticles have passed the cell membranes of organisms. There are no effective methods for qualitative and quantitative estimation of nanoplastics in the environment. Hence, exact amount of nanoplastics present in the environment is not recognized yet.

\section{Limitations}

Particle size of nanoplastics is relatively smaller.

Durability and stability of plastic particles. Heterogeneous nature of the nanoplastics. Investigation procedure is time consuming. Elevated cost of the instrument.

But it is unquestionable that the degradation of microplastics in the environment will continue to form nanoplastics (Mattsson et al., 2015). Furthermore, if nanofragmentation is a significant process, release of nonpolymer nanoscale additives from the fragments of several products may further add to the overall menace (Nowack et al., 2012). It is scrutinized that terrestrial and freshwater resources are the origins and pathways of transport of plastic materials into the oceans (Dris et al., 2015).

Around $80 \%$ of the plastic wastes in the marine ecosystem is considered to be of terrestrial origin (Andrady, 2011) and out of the total produced plastic, a staggering amount of $10 \%$ is expected to end up in the oceans (Barnes et al., 2009). Most of the plastic litter in the water ends up accumulating in the surface of the water body. 
About more than $80 \%$ of the plastic litter cumulates in open-ocean surface waters (Cozar et al., 2014). This plastic litter has the dominant size fraction of those particles less than $10 \mathrm{~mm}$ in diameter (Hidalgo-Ruz et al., 2012). Despite the significant literature describing the sources and impacts of nanoplastics in the ocean (Green et al., 2016), a very little information exists about the hazards and negative effects related to nanoplastics in the freshwater environment (Horton et al., 2017). Because the literature on nanoplastics is quiet narrow, our focus builds on understanding about non-polymer nanomaterials specifically nanoplastics. Present paper outlines the various effects of nanoplastics on marine as well as freshwater systems along with the biota inhabiting in them. Also, various challenges in performing and analyzing ecotoxicity tests with nanoplastics are discussed in this review and viewpoint to future operations and exhortations has been provided.

\section{Sources of nanoplastics in the environment}

Plastics are strong, durable, lightweight and cheap; which makes them suitable for manufacturing of many different products. Various sources of nanoplastics have been suggested such as release from products, emissions from industrial plants or from nanofragmentation of larger particles (Andrady, 2011 and Shim et al., 2014). Release from cosmetic products (da costa et al., 2016), electronics (Blair et al., 2017), paints (Oliveira et al., 2019), drug and biomedical products (Pohlmann et al., 2013) are also some of the primary sources of nanoplastics. Globally there are two main sources of plastics in the aquatic environment viz.

Primary particles (particles manufactured to be in a size range)

Secondary particles (particles derived from larger particles or other structures)
The plastics enter various water systems like oceans, lakes and rivers through solid waste disposal, landfill operations in coastal areas and solid waste disposal from individual vessels at sea. Enormous mass of different types of plastics deposited in landfills without recycling can be easily transported in aquatic environments as plastic debris where it is degraded by different degradation factors (Dumichen et al., 2015).

\section{Sources of nanoplastics in marine environment}

The sources of microplastics in marine environment were mainly from land-based input, coastal tourism, recreational activities, aquaculture and fishing (Browne et al., 2010). Major plastic inputs in sea are from litter generated by ships, wastes carried to the sea by drainage system and rivers, wastes left from various recreational activities, fishing fleets having plastic fishing gear which is lost accidently or careless handling (Pruter, 1987). About $50-80 \%$ of debris from coastline is another source of plastic exposure to aquatic organisms (Thompson et al., 2009). Also, sediment samples from estuarine shorelines contain high amounts of microplastic and nanoplastic particles out of which $65 \%$ are fragments originating from larger pieces of plastic. Astonishingly half of the macroplastic found in the shorelines of estuaries have been originated only from single use packaging items (Browne et al., 2011). In marine environment as compared to terrestrial environment, high salinity and microorganisms facilitates the decomposition of plastic wastes into smaller fragments (Watters et al., 2010).

\section{Sources of nanoplastics in freshwater environment}

For the marine environment, plastic debris from land sources contribute to $80 \%$, emphasizing the important role of the 
freshwater system in the life cycle of plastics (Lambert et al., 2018 and Li et al., 2016). The major pathways of entry into the freshwater environment are atmospheric accumulation of plastics transported by wind and wastewater treatment plants (Lambert et al., 2018 and $\mathrm{Li}$ et al., 2016). Another source of microplastic and nanoplastic in freshwater is consumer products which generally pass through sewers and sewage systems that are later released directly into oceans and lakes (Fendall and Sewell, 2009). Once plastics reach the environment, they may be susceptible to fragmentation and degradation via abiotic and/or biotic processes (da costa et al., 2016 and Mattsson et al., 2018). Although there are several abiotic degradation processes like mechanical, hydrolytic, oxidative and thermal degradation (Mattsson et al., 2018 and Lambert et al., 2014) the most efficient abiotic degradation route for plastics is photodegradation (da Costa et al., 2016). Abiotic degradation develops loss of mechanical and structural properties of plastics which create irregularities in polymer surface that facilitates alteration of physicochemical properties of plastic surface along with the microbial colonization (Harrison et al., 2018).

Apart from abiotic degradation, biodegradation is another important pathway that further degrades plastic shards into nanoplastics in the environment (Trishul and Mukesh, 2010). During the biodegradation, plastics are often degraded outside the bacteria. Also, extracellular enzymes excreted by living microorganisms can easily breakdown the polymer chains in the plastic polymers.

\section{Effects of nanoplastics on aquatic life}

The reported number of different marine species contaminated by microplastics is astonishingly high with more than 690 edible and non-edible marine species (Carbery et al., 2018). In marine species, the microplastic contamination is generally by direct ingestion of microplastics and through trophic transfer. Trophic transfers of nanoplastics in aquatic environment have been investigated by several authors (da costa et al., 2016 and Mattsson et al., 2018). As the size range of microplastics suspended in surface of seawater coincides with the size of plankton and fish eggs, these plastic particles could be readily ingested by many marine species (Boergeret al., 2010). Several synthesized nanoplastics such as polystyrene (PS), polycarbonate (PC), polymethyl methacrylate (PMMA) and PS latex have induced various effects on growth, development, behavior, reproduction and mortality of different organisms such us algae, crustaceans, filter feeders and fishes (da costa et al., 2016 and Mattsson et al., 2018).

\section{Effects ofnanoplastics on primary producers of aquatic life}

Effects hypothesized or demonstrated for nanoplasticin particular include translocation from the intestines into other tissues, oxidative stress, immune response, and particle toxicity (Bhattacharya et al., 2010). Algae serves as starting point of introduction of particle in the aquatic food web (Nowack et al., 2012). Algae are the major primary producers in the aquatic system as the chlorophyll present in them carries out the photosynthetic activities. Algae could have various shapes and even wide variability in sizes ranging from few micrometers to several meters in length. Cellulose containing single celled and multi celled algal species of Chlorella and Scenesdusmus respectively, were studied by Bhattacharya and coworkers in order to investigate the effect of algal morphology on plastic adsorption. During their study, Chlorella and Scenesdusmus were provided with positively charged amidine 
polystyrene and negatively charged carboxyl polystyrene. In order to mimic the natural conditions, the aggregated as well as non aggregated particles were given to algae. It was concluded that positively charged particles were having higher affinity for binding because of the electrostatic interaction between the cellulose present in algal cell wall and the particles (Bhattacharya et al., 2010). Miguel and coworkers studied the impact of nanoplastics released from biodegradable plastic in the freshwater ecosystems (Table 1 and 2).

Table.1 Polystyrene (PS) toxicity in organisms

\begin{tabular}{|c|c|}
\hline Organism & Major findings on effects \\
\hline Chlorella & $\begin{array}{l}\text { Affected algal photosynthesis and promoted reactive } \\
\text { oxygen species (ROS) production (Bhattacharya et al., } \\
\text { 2010). }\end{array}$ \\
\hline Scenedesmus & Increased respiration (Bhattacharya et al., 2010). \\
\hline Brachionus manjavacas & $\begin{array}{l}\text { Reduction in } 50 \% \text { of population due to minimum } \\
\text { concentration of } 0.30 \mu \mathrm{g} / \mathrm{mL} \text {.Reduction in } 89 \% \text { population } \\
\text { due to maximum concentration of } 1.1 \mu \mathrm{g} / \mathrm{mL} \text { (Snell and } \\
\text { Hicks, 2011). }\end{array}$ \\
\hline $\begin{array}{l}\text { EPS from Amphora sp.; } \\
\text { Ankistrodes } \\
\text { musangustus; }\end{array}$ & Affected EPS assembly (Chen et al., 2011). \\
\hline $\begin{array}{l}\text { Mytilus edulis (blue } \\
\text { mussel) }\end{array}$ & $\begin{array}{l}\text { Reduced organism's filtering activity and increased } \\
\text { production of pseudofaeces (Wegner } \text { et al., 2012). }\end{array}$ \\
\hline Daphnia Magna & $\begin{array}{l}\text { Eco-corona formation around particle caused increased } \\
\text { toxicity and affected rate of subsequent feeding (Nasser et } \\
\text { al., 2016). }\end{array}$ \\
\hline Zebrafish (Danio rerio) & $\begin{array}{l}\text { Accumulation of particles in heart and systemic region } \\
\text { along with activation of several biological pathways } \\
\text { related to an immune response in the fish (Veneman et } \\
\text { al., 2017). }\end{array}$ \\
\hline & $\begin{array}{l}\text { Decreased heart rate and alteration in larval behaviour } \\
\text { occurred such as swimming hypoactivity (Pitt et al., } \\
\text { 2018). }\end{array}$ \\
\hline $\begin{array}{l}\text { Oyster(Crassostreagigas) } \\
\text { gametes }\end{array}$ & $\begin{array}{l}\text { Significant increase of ROS production in sperm cells } \\
\text { with anionic particles (Gonzalez-Fernandez et al., 2009). }\end{array}$ \\
\hline
\end{tabular}


Table.2 Major limitations of nanoplastics characterisation techniques (Bhattacharya et al., 2010)

\begin{tabular}{|l|l|}
\hline Technique & Limitations \\
\hline Microscopy techniques & $\begin{array}{l}\text { Sample preparation is a time taking process } \\
\text { and there is no information in the solution } \\
\text { regarding the properties of the nanoplastics } \\
\text { particles. }\end{array}$ \\
\hline Nanoparticle Tracking Analysis & $\begin{array}{l}\text { There is limited number of particles that could } \\
\text { be tracked along with limited tracking } \\
\text { duration. }\end{array}$ \\
\hline Dynamic Light Scattering & $\begin{array}{l}\text { Does not provide the actual size. Also the } \\
\text { technique is biased towards aggregate particles } \\
\text { and large sized particles. }\end{array}$ \\
\hline UV-vis spectrophotometer & $\begin{array}{l}\text { No information on nanoplastics size is } \\
\text { provided. Also there is a shift in the } \\
\text { wavelength with the change in nanoplastics } \\
\text { size. }\end{array}$ \\
\hline
\end{tabular}

They studied the effects of nanoplastics on Anabaena and Chlamydomonas reinhardtii which are involved in various geochemical cycles like carbon cycle and also carry out carbon dioxide sequestration. Anabaena is also involved in important biogeochemical cycles, such as the nitrogen and phosphorus cycles (González-Pleiter, 2019). Polyhydroxybutyrate (PHB) nanoparticles decreased the growth of Anabaena by $90 \%$ and of Chlamydomonas reinhardtii by $95 \%$. The exposure of Polyhydroxybutyrate (PHB) nanoparticles altered the potential of cytoplasmic membrane and increased the depolarization of membrane by $128 \%$ and $181 \%$ in Anabaena and C. reinhardtii respectively, which resulted in either death or growth inhibition of these organisms (González-Pleiter, 2019).

\section{Effects of nanoplasticson consumers of aquatic life}

Daphnia magna, which is an invertebrate commonly found in freshwater systems like ponds and lakes, could ingest nano and micro-sized particles ranging from $20 \mathrm{~nm}$ to $70 \mathrm{~nm}$ (Rosenkranz, 2009). During the studies carried out by Besseling et al., 2014 Daphnia magna was exposed to Polystyrene particles (70 nm in size) and it was reported that Daphnia magna showed higher mortality (six times) when fed with aged algae (a mixture of Scenedesmus obliquus and nanoparticles where Scenedesmus was allowed to ingest the nanoparticles for 5 days before Daphnia received the mixture). It was reported higher absorption of nanoparticles in pre-exposed algae further resulted in higher uptake by Daphnia. Also, a lower reduction in reproductive rate and reduced body size in Daphnia was observed as compared to fresh algae (Besseling et al., 2014). The mussel (Mytilus edulis) and oyster (Crassostrea virginica) were fed with Polystyrene particles (100nm size) and aggregated particles by Ward and his coworkers and it was reported that mussels ingested the aggregated particles at a higher rate as compared to the oyster. They further concluded that the higher gut retention time for mussels and oysters was there along with better ingestion of aggregated particles than that of the nanoplastics. Another study on mussel (Mytilusgallo provincialis) was done and it was reported that exposure of mussel 
to even at low concentrations of about 0.05 $\mathrm{mg} \mathrm{L}^{-1}$ polystyrene changed the gene expression of the organism along with decrease in the enzymatic activities (Brandts et al., 2018). Also polystyrene nanoplastics induced neurotransmission effects and increased the oxidative status which resulted in the peroxidative damage in the organism (Brandts et al., 2018). In long food chains and food webs, the nanoplastics could prominently get bioaccumulated.

The study done on crucian carp (Carassius carassius) where crucian carp was exposed to $24 \mathrm{~nm}$ and $27 \mathrm{~nm}$ sized polystyrene nanoparticles showed that there were changes in the feeding behavior of fish after two months (Mattsson et al., 2015). It was also recorded and analysed that there was increased ethanol levels in fish liver. There was altered fat metabolism and higher concentrations of inosine/adenosine and lysine in muscles of those fishes which were receiving nanoparticles through food chain (Mattsson et al., 2015). In another study Chen et al., 2011 reported that polystyrene nanoplastics with $50 \mathrm{~nm}$ size could result in myelin basic protein in the central nervous system of zebra fish (Danio rerio) along with gene up-regulation significantly inhibiting the activity of acetylcholinesterase (Chen et al., 2011). Further the polystyrene nanoplastics also significantly enhanced the neurotoxic effects in central nervous system of the zebra fish.

A study conducted on embryo and larvae of transparent medaka (Oryzia slatipes) exposed to different polystyrene particles (carboxylated c-50 $\mathrm{nm}$ and c-500 $\mathrm{nm}$ and non-functionalized $50 \mathrm{~nm}$ and $500 \mathrm{~nm}$ ) showed the higher uptake of small sized particles than the larger ones. Perhaps smaller particles $(50 \mathrm{~nm}$ and c-50 nm) were more difficult to excrete as compared to the larger ones $(500 \mathrm{~nm}$ and c-500 $\mathrm{nm}$ ) (Manabe et al., 2011).

\section{Challenges and fate of nanoplastics}

Retrieving of nanoplastics particles from environment and collection of representative samples is the first challenge in measuring the nanoplastic contamination as both abiotic and biotic samples may contain organic matter, mineral constituents and water. Further, prevention of sample contamination from equipments, reagents, air etc. in the laboratory is also a matter of concern for the nanoplastics analysis. In addition, better quality control and quality assurance need to be implemented in the laboratory (Toussaint et al., 2019). Furthermore, smaller size of nanoparticles and choice of particle shapes included for the studies (fragments, sheets, spheres, ropes, pellets and fibers) also affects the analysis of the plastic particles. Also variability in conditions during sample collection and analysis could contaminate the samples and further affect the analysis (Foekema et al., 2013). Reported microplastic concentrations may also vary due to exclusion of fibers, inclusion of all particle shapes irrespective of methodology used (Lusher, 2015). Various methods for isolation of nano- or microplastic from the samples for plastic analyses have been applied like density, removal of organic matter with acids, bases, peroxide and enzymes, sieving, and decomposing or drying samples at different temperatures (Hidalgo-Ruz et al., 2012). Followed by proper cleaning of the collected samples, detection of microplastics particles is generally done by inspecting visually and through spectra using techniques of polymer identification like FTIR and Raman spectroscopy. The adsorption of can be determined by absorbance analysis using UV-vis spectroscopy and microplate readers (Bhattacharya et al., 2010). The use of microscopy imaging, such as fluorescence microscopy (Bergami et al., 2017), SEM 
(Bergamiet al., 2017), Environmental Scanning Electron Microscopy (ESEM) (Bhattacharya et al., 2010) is used to study nanoplastics adsorption onto algae.

Many of the above mentioned techniques are mainly focusing on problems associated with macro and micro forms of the plastic present in the marine and freshwater environment. Matrix effects, sample protocols not following quality assurance, false positives etc. could result in false data interpretation leading to incorrect information. Combination characterisation steps for plastic characterisation, pollution event determination, chemometrics for data processing and analysis could significantly improve the way of plastic characterisation. Rapid diagnostic techniques such as NIR or MIR techniques would also serve as a boon in nanoplastics characterisation and analysis. Rather than implementing the complex matrix, full characterisation of laboratory based assays is needed which could significantly help in better understanding of nanoplastics in the aquatic environment and its toxicological and hazardous impacts in the aquatic organisms. Deep understanding regarding the plastics and its impacts and development of advanced tools for the nanoplastics analyses will not only provide reliable information but will also enhance the overall environmental health.

\section{References}

ForouharVajargah, M., MohamadiYalsuyi, A., Hedayati, A. and Faggio, C.2018. Histopathological lesions and toxicity in common carp (Cyprinus carpio L. 1758) Induced by copper nanoparticles. Microscopy research and technique, 81(7): 724-729.

Vlachopoulos, J. and Strutt, D. 2003. Polymer processing. Mater SciTechnol, 19(9):1161-1169.
Brandsch, J. andPiringer, O.2008. Characteristics of plastic materials. Plastic packaging. Wiley-VCH Verlag GmbH \& Co. KGaA, Weinheim, 1561.

Plastics Europe, 2016. Plastics- the Facts 2016. An analysis of European plastics production, demand and waste data, Association of Plastics Manufacturers, Brussels.

Rochman, C.M. and Browne, M.A. 2013. Classify plastic waste as hazardous. Nature, 494 (7436):169-171.

Horton, A.A., Walton, A., Spurgeon, D.J., Lahive, E. and Svendsen C. 2017. Microplastics in freshwater and terrestrial environments: evaluating the current understanding to identify the knowledge gaps and future research priorities. Sci. Total Environ, 586:127-141.

Xiong, X., Zhang, K., Chen, X., Shi, H., Luo, Z. and $\mathrm{Wu}$, C. 2018b. Sources and distribution of microplastics in China's largest inland lake - qinghai Lake. Environ. Pollut, 235:899.

Mendoza, L.M.R., Karapanagioti, H. and Alvarez N.R. 2018. Micro (nanoplastics) in the marine environment: current knowledge and gaps. Current Opini. Environ. Sci. Health, 1: 47-51.

Zhang, G.S. and Liu, Y.F. 2018. The distribution of microplastics in soil aggregate fractions in southwestern China. Sci. Total Environ, 642:12-20.

Abidli, S., Antunes, J.C., Ferreira,J.L., Lahbib, Y., Sobral, P. and Menif, N.T.E. 2018. Microplastics in sediments from the littoral zone of the north Tunisian coast (Mediterranean Sea). Estuarine Coastal and Shelf Science, 205:1-9.

Cozar, A., Martí, E., Duarte, C., Garcíadelomas, J., Sebille, E.V. and Ballatore $\mathrm{J}$ et al. 2017. The arctic 
ocean as a dead end for floating plastics in the north Atlantic branch of the thermohaline circulation. Science advances, 3(4): 1600582.

Munari, C., Infantini, V., Scoponi, M., Rastelli, E., Corinaldesi, C. andMistri, M. 2017. Microplastics in the sediments of terra nova bay (ross sea, Antarctica). Marine pollution bulletin, 122(1-2):161-5.

Shen, M., Zhu, Y., Zhang, Y., Zeng, G., Wen, $\mathrm{X}$. and Yi Het al.2019. Micro(nano)plastics: unignorable vectors for organisms. Marine pollution bulletin, 139:328-331.

Thompson, R.C., Olsen, Y., Mitchell, R.P., Davis, A., Rowland, S.J. and McGonigle Det al.2004. Lost at sea: where is all the plastic? Science, 304:838.

Lei, K., Qiao, F., Liu, Q., Wei, Z., Qi, H. and Cui, S.et al.2017. Microplastics releasing from personal care and cosmetic products in China. Marine pollution bulletin, 123:122.

Hidalgo-Ruz, V., Gutow, L., Thompson, R.C. and Thiel, M.2012. Microplastics in the marine environment: a review of the methods used for identification and quantification, Environ. Sci. Technol. 46:3060-3075.

El Hadri, H., Gigault, J., Maxit, B., Grassl, B. and Reynaud, S.J.N. 2020. Nanoplastic from mechanically degraded primary and secondary microplastics for environmental assessments. NanoImpact. 17:100206.

Jambeck, J.R., Geyer, R., Wilcox, C., Siegler, T.R., Perryman, M. and Andrady, A.et al.2015. Plastic waste inputs from land into the ocean. Science, 347(6223):768-771.

Klaine, S.J., Alvarez, P.J.J.,Batley, G.E., Fernandes,T.F., Handy, R.D. and Lyon, D.Y.et al.2008. Environmental Toxicology and Chemistry. 27(9):
1825-1851.

Klaine, S.J., Koelmans, A.A., Horne, N., Handy, R.D., Kapustka, L. and Nowack, B.et al.2012. Paradigms to assess the environmental impact of manufactured nanomaterials. Environmental Toxicology and Chemistry. 31:3-14.

Velzeboer, I., Kwadijk, C.J.A.F. andKoelmans, A.A. 2014a. Strong sorption of PCBs to nanoplastics, microplastics, carbon nanotubes and fullerenes. Environmental Science and Technology, 48:4869-4876.

Mattsson, K. Hansson, L.A. andCedervall, T. 2015. Nano-plastics in the aquatic environment. Environ. Sci. Process. Impacts. 17:1712-1721.

Nowack, B., Ranville, J., Diamond, S., Gallego-Urrea, J., Metcalfe, C. and Rose, J.et al.2012. Potential scenarios for nanomaterial release and subsequent alteration in the environment. Environmental Toxicology and Chemistry, 31:50-59.

Dris, R., Imhof, H., Sanchez, W., Gasperi, J., Galgani, F., Tassin, B. andLaforsch, C.2015. Beyond the ocean: contamination of freshwater ecosystems with (micro-) plastic particles, Environmental chemistry, 12(5):539-550.

Andrady,A.L.2011. Microplastics in the marine environment. Marine Pollution Bulletin, 62:1596-1605.

Barnes, D.K., Galgani, F., Thompson, R.C. andBarlaz, M.2009. Philosophical transactions of the Royal Society of London. Series B, Biological sciences, 364(1526):1985- 98.

Cózar, A., Echevarría, F., Ignacio, González-Gordillo, J., Irigoien, X., Úbeda, B. and HernándezLeón, S.et al.2014. Plastic debris in the open ocean. Proceedings of the National Academy of Sciences, 111(28):10239- 
10244

Green, D.S., Boots, B., Sigwart, J., Jiang, S. and Rocha, C. 2016. Effects of conventional and biodegradable microplastics on a marine ecosystem engineer (Arenicola marina) and sediment nutrient cycling, Environmental pollution, 208:426434.

Horton, A.A., Walton, A., Spurgeon, D.J., Lahive, E. and Svendsen, C.2017. Microplastics in freshwater and terrestrial environments: evaluating the current understanding to identify the knowledge gaps and future research priorities, Sci. Total Environ., 586:127-141.

da Costa, J.P., Santos, P.S., Duarte, A.C. and Rocha-Santos,T.2016. (Nano) plastics in the environment-sources, fates and effects. Science of the total environment, 1:566:15-26.

Oliveira, M., Almeida, M. and Miguel. 2019. A micro (nano) plastic boomerang tale: A never ending story? TrACTrends in Analytical Chemistry, 1:112:196-200.

Pohlmann, A.R., Fonseca, F.N., Paese, K., Detoni, C.B., Coradini, K., Beck, R.C. and Guterres, S.S. 2013. Poly ( $€-$ caprolactone) microcapsules and nanocapsules in drug delivery. Expert opinion on drug delivery TrACTrends in Analytical Chemistry, 10 (5):623638.

Dümichen, E., Barthel, A.K., Braun, U., Bannick, C.G., Brand, K., Jekel, M. and Senz, R. 2015. Analysis of polyethylene microplastics in environmental samples, using a thermal decomposition method, Water Research, 85:451-457.

Browne, M.A., Galloway, T.S. and Thompson, R.C. 2010. Environ SciTechnol, 44(9): 3404-9.

Pruter, A.T. 1987. Sources, quantities and distribution of persistent plastics in the marine environment. Marine pollution bulletin, 18:(6):305-310.

Thompson, R.C., Moore, C.J., VomSaal, F.S. and Swan, S.H. 2009. Philosophical transactions of the Royal Society of London. Series B, Biological sciences, 364(1526):215366.

Browne, M.A., Crump, P., Teuten, E., Tonkin, A., Galloway, T. and Thompson, R. 2011. Accumulation of microplastic on shorelines woldwide: sources and sinks. Environ. Sci. Technol., 45(21):9175-9179.

Watters, D.L., Yoklavich, M.M., Love, M.S. and Schroeder, D.M. 2010. Assessing marine debris in deep seafloor habitats of California. Marine Pollution Bulletin, 60:131-138.

Lambert, S. and Wagner, M. 2018. Freshwater Microplastics: Emerging Environmental Contaminants?, ed. M. Wagner and S. Lambert, Springer International Publishing, 1-23

Li, W., Tse, H. and Fok, L. 2016. Plastic waste in the marine environment: A review of sources, occurrence and effects, Sci. Total Environ., 566:333349.

Fendall, L.S. and Sewell, M.A. 2009. Contributing to marine pollution by washing your face: microplastics in facial cleansers. Marine pollution bulletin, 58(8):1225-1228.

Mattsson, K., Jocic, S., Doverbratt, I. and Hansson. 2018. Nanoplastics in the aquatic environment. Microplastic Contamination in Aquatic Environments, 379-399.

Lambert, S., Sinclair, C. and Boxall, A.2014. Reviews of Environmental Contamination and Toxicology, Springer, vol.227:1-53.

Harrison, J.P., Hoellein, T.J., Sapp, M., Tagg, A.S., Ju-Nam, Y. and Ojeda, J.J. 
2018. Freshwater Microplastics: Emerging Environmental Contaminants? Springer International Publishing, Cham, 181-201.

Trishul, A. andMukesh, D.2010. Biodegradation of aliphatic and aromatic polycarbonates. Macromol. Biosci.,8:14-24.

Carbery, M., O'Connor, W. andThavamani, P. 2018. Trophic transfer of microplastics and mixed contaminatns in the marine food web and implications for human health. Environ Int.,115:400-409.

Boerger, C.M., Lattin, G.L., Moore, S.L. and Moore, C.J. 2010. Plastic ingestion by planktivorous fishes in the North Pacific Central Gyre. Marine pollution bulletin,60(12):2275-2278.

Bhattacharya, P., Lin, S., Turner, J.P., andKe, P.C. 2010. Physical adsorption of charged plastic nanoparticles affects algal photosynthesis. The Journal of Physical Chemistry C, 114 (39):16556-16561.

González-Pleiter, M., Tamayo-Belda, M., Pulido-Reyes,G., Amariei, G., Leganés, F., Rosal, R.et al. 2019. Secondary nanoplastics released from a biodegradable microplastic severely impact freshwater environments. Environmental Science, 6(5):13821392.

Snell, T.W. and Hicks, D.G.2011. Assessing toxicity of nanoparticles using Brachionus manjavacas (Rotifera). Environmental toxicology, 26(2):146152.

Chen, C.S., Anaya, J.M., Zhang, S., Spurgin, J., Chuang, C.Y., Xu, C. et al. 2011. Effects of engineered nanoparticles on the assembly of exopolymeric substances from phytoplankton. PLoS One, 216(7): 21865.

Wegner, A., Besseling, E., Foekema, E.M.,
Kamermans, P., Koelmans, A.A. 2012. Effects of nanopolystyrene on the feeding behavior of the blue mussel (Mytilus edulis L.). Environmental Toxicology and Chemistry, 31(11):2490-2497.

Nasser, F. and Lynch, I.2016. Secreted protein eco-corona mediates uptake and impacts of polystyrene nanoparticles on Daphnia magna. Journal of proteomics, 137:45-51.

Veneman,W.J., Spaink, H.P., Brun, N.R., Bosker, T. and Vijver, M.G. 2017. Pathway analysis of systemic transcriptome responses to injected polystyrene particles in zebrafish larvae. Aquatic Toxicology, 190:112120.

Pitt, J.A., Kozal, J.S.,Jayasundara, N., Massarsky, A., Trevisan, R., Geitner, N.et al. 2018. Uptake, tissue distribution, and toxicity of polystyrene nanoparticles in developing zebrafish (Danio rerio). Aquatic toxicology, 194:185-194.

González-Fernández, C., Tallec, K., Le Goïc, N., Lambert, C., Soudant, P., Huvet, A.et al.2018. Cellular responses of Pacific oyster (Crassostrea gigas) gametes exposed in vitro to polystyrene nanoparticles. Chemosphere, 208:764-772.

Rosenkranz, P., Chaudhry, Q., Stone,V. andFernandes, T.F.2009. A comparision of nanoparticle and fine particle uptake by Daphnia magna. Environmental toxicology and chemistry, 28(10)2142-2149.

Besseling, E., Wang, B., Lurling, M. andKoelmans, A.A. 2014. Nanoplastic affects growth of $S$. obliquus and reproduction of D. magna. Environmental science and technology, 48(20):12336-12343.

Brandts, I., Teles, M., Gonçalves, A.P., Barreto, A., Franco-Martinez, L., 
Tvarijonaviciute, A.et al.2018. Effects of nanoplastics on Mytilusgallo provincialis after individual and combined exposure with carbamazepine. Sci. Total Environ, 643:775-784.

Chen, Q., Yin, D., Jia, Y., Schiwy, S., Legradi, J., Yang, S.et al. 2017. Enhanced uptake of BPA in the presence of nanoplastics can lead to neurotoxic effects in adult zebrafish. Sci. Total Environ., 609: 1312-1321.

Manabe, M., Tatarazako, N. and Kinoshita,M.2011. Uptake, excretion and toxicity of nano-szed latex particles on medaka (Oryzias latipes) Aquatic Toxicology, 105(3-4):576581.

Toussaint, B., Raffael, B., Angers-Loustau, A., Gilliland, D., Kestens, V. and Petrillo, M.et al. 2019. Review of micro-and nanoplastic contamination in the food chain. Food Additives \& Contaminants. Part A, 4:36(5): 63973.

Foekema, E.M., De Gruijter, C., Mergia, M.T., Murk, A.J., Van Franeker, J.A. andKoelmans, A.A.2013. Plastic in North Sea fish. Environmental Science \& Technology, 47(15): 8818-8824.

Lusher, A. 2015. Microplastics in the marine environment: distribution, interactions and effects. Marine anthropogenic litter Cham: Springer International Publishing, 245-307.

Bergami, E., Pugnalini, S., Vannuccini, M., Manfra, L., Faleri, C., Savorelli, F.et al.2017. Long-term toxicity of surface-charged polystyrene nanoplastics to marine planktonic species Dunaliella tertiolecta and Artemia franciscana. Aquatic Toxicology, 189: 159-169.

\section{How to cite this article:}

Prerna Rathor, Alfred Mech, Naveed Anayat, Tushar Subhra Khanra, Zhovi Ringa and Saikat Maity. 2021. A Review on Interaction of Nanoplastics with Aquatic Environment and Organisms. Int.J.Curr.Microbiol.App.Sci. 10(02): 3189-3200.

doi: https://doi.org/10.20546/ijcmas.2021.1002.350 